\title{
DIGITAL TRANSFORMATIONS AND MUSICAL EDUCATION ON THE TRADITIONS OF FOLK INSTRUMENTAL CULTURE
}

\author{
Dmitrii Rytov \\ rytovda@mail.ru
}

Saint Petersburg State University of Culture, Russia

\begin{abstract}
The paper presents the peculiarities of introduction of digital technologies in musical education on traditions of folk instrumental culture, the potentials of building an educational process on the basis of centuries-old traditions of the Russian people, its richest cultural heritage, in particular, folk art culture. Functions of folk art culture are shown and analyzed. The core viewpoint of the paper is showing the importance of knowledge and respect for own culture as a guarantor of self-preservation of the ethnic group, strengthening of social self-awareness, formation of tolerant relationships and relationships with other ethnic groups. The importance of folk instruments in children's musical education is considered. The possibilities of solving the problem of archiving of cultural heritage products and providing them with full access are explored. Modern opportunities of distance education and use of digital technology resources in music education are demonstrated.
\end{abstract}

Keywords: Folk Art Culture; Cultural Heritage; Traditions of Folk Instrumental Culture; Translation of Cultural Values; Digital Technologies; Information Environment; Distance Education

\section{ЦИФРОВЫЕ ТРАНСФОРМАЦИИ И МУЗЫКААЬНОЕ ОБРАЗОВАНИЕ НА ТРААИЦИЯХ НАРОАНОЙ ИНСТРУМЕНТААЬНОЙ КУАЬТУРЫ 1}

\author{
АМитрий Рытов \\ Санкт-Петербургский государственный институт культуры, Россия \\ Резюме: Раскрыты особенности внедрения цифровых \\ технологий в сорере музыкального образования на тралициях \\ народной инструментальной культуры. Показаны потенциалы \\ построения образовательного процесса на основе многовековых \\ тралиций русского народа, его богатейшего культурного наследия, \\ в частности, народной художественной культуры. Показаны и \\ проанализированы функции народной художественной культуры. \\ Актуализировано значение знания и уважения культуры своего
}

1 В статье публикуются результаты Аокиала, представленного на конореренции LCH 2019 
народа как гаранта самосохранения этноса, укрепления социального самосознания, формирования толерантных взаимосвязей и взаимоотношений с Аругими этносами. Рассмотрено значение народных инструментов в музыкальном образовании Аетей. Раскрыты возможности решения проблемы архивации продуктов культурного наследия и обеспечения К ним полноценного Аоступа. Продемонстрированы современные возможности Аистанционного образования и использования ресурсов цифрровых технологий в музыкальном образовании.

КАючевые слова: народная художественная культура; культурное наследие; традиции народной инструментальной культуры; трансляция культурных ценностей; цифровые технологии; инорормационная среда; Аистанционное образование

Современные реалии констатируют все большее развитие цифровых технологий, Аемонстрацию различных фрорм цифрровых трансорормаций, с прослеживающейся тенденцией перехола от производства материальных продуктов $\mathrm{k}$ произво Аству цифрровых продуктов. Стоит отметить, что процесс интеграции цифровых технологий практически во все области Аеятельности человека несет за собой глобальные изменения и видоизменения, в том числе, и в сореру культуры и образования. Меняются не только принципы и алгоритмы созАания новых продуктов и сохранения имеющихся, но меняется и сам человек, который оказывается в новой инорормационной среде, требующей перестройки мышления, восприятия и обработки информации. Стоит обратить внимание, что все эти тенАенции непосредственно касаются и ребенка, процессов его образования и воспитания.

Мир детства современного ребенка полон вызовов и проблем. Констатируется перенасыщенность окружающего ребенка инорормационного пространства, системно меняются процессы обработки и орильтрации инорормации, возникают Аеструктивные явления, ведущие к галжатизации сознания маленького человека, замкнутого в мир только виртуального общения.

Недостаток реального общения велет к Аеорормации культурных и социальных ценностей, межличностных взаимоотношений. С олной стороны, внеАрение цифровых технологий позволяет быстро и оперативно решать вопросы, получать необходимую инорормацию, а с Аругой стороны, теряется «теплое», аналоговое общение человека с 
окружающим миром. Возникают закономерные вопросы: куда мы илем, зачем илем именно туда и что Аелаем? Ситуация решения этих противоречий свидетельствует о необхоАимости Новых поАХоАОв, в том числе, в сорере музыкального образования на тралициях народной инструментальной культуры. Построение модели образовательного процесса на основе многовековых тралиций русского нарола, его богатейшего культурного наслеАия, в частности, народной художественной культуры, является в настоящее время особенно актуальной. Знание и уважение культуры своего народа выступает определенным гарантом самосохранения этноса, укреплением социального самосознания, а также созАает предпосылки $А \wedge я$ формирования толерантных взаимосвязей и взаимоотношений с Аругими этносами. В толковом словаре К. Ожегова понятие культура фрормулируется как совокупность производственных, общественных и Ауховных Аостижений мюлей (Ozhegov and Shvedova, 2006: 313). Становление и развитие культуры невозможно без бережного отношения к тралициям. В фрилософрском словаре Аано определение тралиции. Это исторически сложившиеся и передаваемые от поколения к поколению обычаи, обряды, общественные установления, илеи и ценности, нормы поведения и т.п.; элементы социально-культурного наследия, сохраняющиеся в обществе или в отАельных социальных группах в течение Алительного времени (Frolova, 2001: 577). «Народная художественная культура является частью художественной культуры общества.

Она развивается пол влиянием принятых и утверАившихся в Аанном обществе художественных норм, ценностей и илеалов. Спецификой народной художественной культуры является то, что она воплощает в себе традиции (то есть устойчивые фрормы жизни народы, отражающие особенности его национального характера и национальных образов мира)» (Baklanov and Streltsov, 2000: 36).

Народная художественной культура имеет фонкции: познавательную, мировоззренческую, социализирующую. Если прямое сакральное, обряловое, приклалное назначение наролной художественной культуры в современное время может быть не так ярко выражено и фрункционально, но оно трансорормируется в систему 
важных принципов, понятий и категорий, создающих знание и понимание своей истории, своей культуры, своей общности. Я.В. Чеснов отмечает, что «виля в народной фольклорной культуре живой организм, мы констатируем не только ее поАвиЖность, аАаптивность и системность. Нужно подчеркнуть целевую самостоятельность всей народной культуры, ее способность предшествовать многим социальным и ментальнопсихическим установкам, фоормирующих мичность (Chesnov, 2014: 30). Неразрывность связи поколений создает соеАинительный культуросозиАающий фунАамент из ценностей прош^ого А^я буАущего.

В этом контексте этнокультура, которая имеет огромное количество значений в различных областях человеческой жизнедеятельности, может проявляться и как культурная норма, выраженная в традициях, обычаях, ритуалах характерных $А \wedge я$ определённого этноса. Аинамичные изменения, происходящие в системе образования и воспитания России, требуют новых поАхо АОв К СозАанию условий Аля всестороннего развития ребенка, его социального воспитания, обращения к имеющимся ценностям, которые помогут сбалансировать образовательные и воспитательные стратегии в век цифровых технологий. Стратегически важной залачей является формирование неразрывности связи поколений через созАание культуросозиАающего фрунАамента из наследия прошлого Аля будущего, а также оптимальность при использовании современных цифровых технологий. Ресурсы народной музыкальной культуры, народных музыкальных инструментов влияют на всестороннее гармоничное развитие ребенка, активное познание окружающего мира, позволяют осуществлять социализацию ребенка в системе культурных ценностей родной культуры. Ребенок слышит родную речь, мелодику напевов, голоса инструментов своего народа - все это позволяет на генетическом уровне обратиться к тому, что было большое количество лет назал. Это очень важная и мощная полпитка, которая позволяет ребенку выходить на совершенно новый уровень. Это и формирование национальной самоилентичности и гармонизация межкультурных взаимоотношений, построенных на принципах толерантности и взаимоуважения. Народная музыкальная культура является олним из среАств, когАа через уважительное отношение к своей культуре формируется взаимоуважением к культуре других 
народов. Стоит обратить внимание, что в процессе музицирования, игры на народных инструментах возникает Аинамичное коммуницирование с Аругими Аетьми. Причем, не только на уровне музыкального взаимолействия, но и на уровне выстраивания общих межличностных взаимоотношений и общения. Аети, которые играют в ансамбле (коллективе, команде), выполняющем определенные залачи, начинают по Аругому относиться Аруг к Аругу, более внимательно прислушиваются к мнению человека, который находится рядом и участвует в музыкальном проекте. Также важным моментом является формирование мичностных качеств, позволяющих решать не только узкопроффильные залачи, но и которые позволяет решать вопросы формирования общежизненных умений. Можно вспомнить высказывания Аревнегреческих мыслителей, которые при исслеАовании человека обращали внимание на гармоничный синтез его качеств. Так Аристотель вылелял три стороны воспитания: фоизическое, нравственное и умственное. А во время обучения в школе он на олин уровень стави^ изучение математики, астрономии, митературы, истории, фрилософрии И МузыкИ.

Включение в процесс музыкального образования народных инструментов значимо, так как они выступают в роли Символов носителей звуковой национальной самобытности, которые имеюет свой оригинальный, неповторимый звук. Ребенок «купается» в их тембровой палитре, он музыкально-эстетически развивается, пробует, ищет, изучает, обращается к истокам своего народа. На уровне становления звуковых представлений у ребенка происхолит орормирование основ бережного отношения не только к народной музыке, но и к музыке разных жанров: классической, Ажазовой, эстралной и $А р$.

Ролство звукообразующих и формообразующих параметров народных инструментов позволяет ребенку в русле родных представлений ^учше понимать свойства инструментов (погремушки, трещотки, рубели, свистульки, жалейки и Ар.). Ребенок сразу погружается в определенные социокультурные процессы. Игра на народных инструментах, из-за их относительной простоты освоения, позволяет сразу вкАючать ребенка в музыкальную Аеятельность, заниматься ему звукообразованием и звукотворчеством. Взяв в руки 
^ожки И^И Аругой простейший народный инструмент, он сразу начинает играть, творить. Это - мотивационная предпосылка. Ребенок заинтересован. Колмективные формы музицирования позволяют созиАательно взаимодействовать с Аругими участниками ансамбля. Народные инструменты преАоставляют ребенку возможность вкАючиться в многослойную развивающую среАу фрормирования музыкальных залатков и раскрытия своих потенциалов. Это своеобразный мотивационный аккумулятор Аля изучения и акалемических инструментов. Причем, меняется вектор их изучения. Происхолит отход от позиции потребления, а усиливается роль решения образовательных залач с позиции комлеги, партнера. ЕАиное звено: ребенок-МУЗЫКАНТ и профрессиональный МУЗЫКАНТ.

В рамках реализации инфоомационно-просветительской фрункции кажАый народный инструмент - это путь к изучению традиций определенного региона, анализа конструктивных особенностей инструментов определенной местности. Немаловажно, как изучаются и транслируются культурные ценности в современных реалиях. При потере прямой репрезентации изначальных фрункций инструментов (утилитарных, сигнальных, обрядовых) акцент переносится на культурологический и образовательный аспекты их применения в музыкальной Аеятельности. Можно продемонстрировать свое умение играть на инструменте на различных фестивалях, конкурсах, концертах.

Участие в этих мероприятиях обеспечивает также общение и взаимообогащение в среле увлеченных этим направлением музыкального исполнительства ^юАей. Как виАно, народная музыкальная культура и народные музыкальные инструменты имеют огромные культурные и воспитательные потенциалы в музыкальном образовании детей, которые могут быть усилены за счет использования современных цифровых технологий, трансорормации их возможностей. А^я Аетей очень важно знакомиться с ^учшими образцами культурного наследия своего народа. При этом Аостаточно остро стоит проблема архивации продуктов культурного наслеАия и обеспечения к ним полноценного Аоступа. Фиксация на различных электронных, цифрровых носите^ях этих продуктов выступает в статусе более Аолговечного способа сохранения инорормации. Стоит только обратить внимание на предоставление 


возможности архивации материалов не только резервным
копированием на Аругой носитель (backup сору), но и созАании многоуровневой системы резервации инорормации, в том числе, на разных типах носителей. Механизмы, электроника подвержены различным виАам поломкам, выхоАит из строя. Многоуровневое копирование позволит обеспечить Аолговечность сохраняемой инорормации и обеспечит ее Аоступность и использование на протяжении Алительного времени. Различные сайты, медийные источники, интернет-энциклопеАии позволяют реализовывать информационную функцию - предоставлять инорормацию об исполнителях на народных инструментах, о творческих коллективах, играющих на этих инструментах. Творческая функция реализуется в режиме самопредставления творческих еАиниц с помощью созАанных ими визитных карточек в форме персональных сайтов, ютуб-каналов и Ар. Африши выступлений исполнителей выступают в роли опреАеленного портоолио, которое позволяет фииксировать творческие Аостижения колмективов, творческие портреты-истории становления и развития исполнителя. Профрильные интернет-ресурсы и размещенные на них проекты позволяют не только фиксировать, структурировать творческие еАиницы по направлениям Аеятельности, но и обеспечивают возможность общения музыкантов Аруг с Аругом, получать информацию о мероприятиях с помощью электронных ресурсов. Предоставление методической помощи обеспечивает проведение мастер-классов веАущих исполнителей на народных инструментах, использование наукометрических баз, позволяющих большому количеству заинтересованных ^иц получить метолическую инорормацию по интересующим их проблемам.

Размещение научно-метолических материалов в интернете, в социальных сетях позволяет расширять инорормационное поле $А \wedge я$ публикации материалов и Аля их изучения. Все большую популярность получают различные Аистанционные формы обучения при проведении научно-методических мероприятий, в том числе и в системе музыкального образования. Вилеоконференции очень удобны как $А \wedge я$ веАущего, лектора, так и Аля участников этого мероприятия. Практически в ^юбой точке света можно подкАючиться и принять участие 
в работе вилеоконференции, показать и продемонстрировать свои знания, имеющийся опыт. Форма вебинара позволяет не только Аать инорормацию, продемонстрировать практические навыки, но и в онлайн-режиме обмениваться рекоменАациями, уточнять и Аополнять инорормацию, осуществлять консультирование в чате.

Использование электронных средств обучения позволяет с помощью мультимеАийных среАств и полбора среАств обучения осуществлять активное и целенаправленное художественно-творческое взаимолействие и обучение пелагога с обучающимися. Слелует обратить внимание, что открыты возможности, при подАержке соответствующих государственных, грантовых программ, проводить Аистанционное образование бесплатно. Различные типы компьютерных срелств (презентации, электронные энциклопеАии, электронные учебники и электронные учебные курсы, музыкальные приклалные программы, облачные сервисы Аля хранения и демонстрации информации) позволяют процесс музыкального образования насыщать новыми возможностями, способствующими повышению уровню эорорективности обучения. ОАнако, обучение музыканта-исполнителя с помощью только Аистанционных технологий невозможно, так как не булет хватать оперативной коррекции процесса обучения, «живого» общения межАу педагогом и исполнителем и ситуативного отклика при многомерности решаемых образовательных и исполнительских залач, энергетического и эмоционально-чувственного восприятия исполняемой музыки. Немаловажно отметить, что игра на народных инструментах, относящихся изначально к музыкальным орудиям бесписьменной передачи инорормации, требует персонального отклика музыканта на исполняемую музыку. Музыкальная Аеятельность в этом случае не связана с чтением и Аальнейшим воспроизведением нотного текста. Происхолит инАивидуальное переосмысление музыкального материала, импровизация на основе мичных умений влаления инструментом, уровня Ауховного опыта, умения передать музыкальную мысль через свои исполнительские и творческие возможности. Применение цифровых технологий в Аанном случае возможно только Аля фиксации и Аальнейшего воспроизведения исполненного, перелаче и обработке записанной инорормации. 
В заключении можно констатировать, что использование цифровых технологий в музыкальном образовании на традициях народной инструментальной культуры не являются самоцелью, так как не может заменить или вытеснить априорную ценность этого феномена в первозданном виле, силу его музыкально-педагогического возАействия. ОАнако использование стремительно развивающихся цифровых технологий может выступать в роли гибкого и современного инструмента сопровожАения процесса музыкального образования, Аополнения его новыми возможностями.

\section{Аитература / References}

Baklanov, T. I.; Streltsov, E. Yu. (eds.) (2000). Folk Art Culture: Textbook / Ed. Baklanov T.I., Streltsov E.YU. - M : MGUKI, 2000 .- 344 p. (In Russian) / [HapoAHaя художественная культура: Учебник / ПоА реА. Баклановой Т.И., Стрельцовой Е.Ю. - М.: МГУКИ, 2000. - 344 с.]

Chesnov, Ya. V. (2014). Philosophical anthropology of folk culture / Ya. V. Chesnov. M : Canon + ROOI "Rehabilitation", 2014 (In Russian) / [Чеснов Я. В. Филосодрская антропология народной культуры / Я. В. Чеснов. - М.: Канон + РООИ «Реабилитация», 2014]

Frolova, I. T. (ed.) (2001). Philosophical Dictionary / Ed. I.T. Frolova. - 7th ed., Revised. and add. - M $\therefore$ Republic, 2001 (In Russian) / [Фи^ософрский словарь / ПоА рел. И.Т. Фролова. - 7-е изА., перераб. и лоп. - М.: Республика, 2001]

Ozhegov, S. I.; Shvedova N. Yu. (2006). Explanatory Dictionary of the Russian Language: 80,000 words and phraseological expressions / Russian Academy of Sciences. Russian Language Institute V.V. Vinogradova. - 4th ed., Revised. - M : LLC "A TEMP", 2006 (In Russian) / [Ожегов С.И. и ШвеАова Н.Ю. Толковый словарь русского языка: 80000 слов и фразеологических выражений / Российская акалемия наук. Институт русского языка им. В.В. Виноградова. - 4-е изА., Аополненное. - М.: ООО «А ТЕМП», 2006] 


\section{КУАТУРНО-ИСТОРИЧЕСКО НАСАЕАСТВО: \\ ОПАЗВАНЕ, ПРЕАСТАВЯНЕ, АИГИТААИЗАЦИЯ}

\section{CULTURAL AND \\ HISTORICAL \\ HERITAGE}

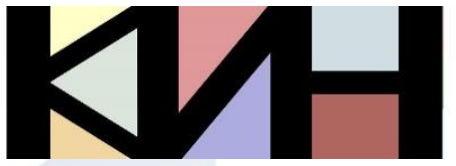

PRESERVATION PRESENTATION DIGITIZATION

\section{Съставители \\ Галина БогАанова Ваня Матеева}

Материалите в сборника са обект на авторско право. Разрешава се безвъзмезАното ползване на техни електронни/ хартиени копия само за лична употреба или обучение, при пьлно цитиране на текущата страница и слеА писмена Аекларация от цитиращия за Аипса на тьрговски намерения. За копиране поА Аруга фрорма, препубликуване или публикуване на сървьри се изисква писмено разрешение и/или заплащане.

() Авторски колектив, 2019 Технически реАактори: Николай Ноев Калина Сотирова-Вълкова Ка^оян Николов

\section{Editors}

Galina Bogdanova Vanya Mateeva

This work is subject to copyright. Open and free of charge use of digital/hard copies of publications is granted only for personal or educational use, with full citation of the current page, and after written declaration of the quoting side for not-commercial Intention. For any other reproducing types, republishing, photocopying, recording, or any other storage retrieval system/ server written permission and/or fee is required.

() Authors` Group, 2019

Technical editors:

Nikolay Noev

Kalina Sotirova-Valkova

Kaloyan Nikolov

\section{Научна поредица: том 5, брой 2 (7)/2019}

Science series: vol. 5 , issue $2(7) / 2019$

www.math.bas.bg/vt/kin

ISSN: 2367-8038 